\title{
Noninvasive predictors of atrial fibrillation: age, sex, interatrial block, and left atrial enlargement
}

\section{Enes Abdović*}

Cantonal Hospital Zenica, Zenica, Bosnia and Herzegovina
RECEIVED:

September 25, 2016

ACCEPTED:

October 10, 2016

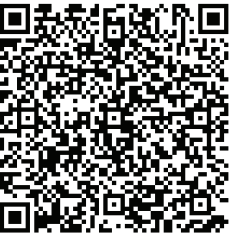

KEYWORDS: atrial fibrillation, noninvasive predictors, interatrial block, left atrial enlargement. CITATION: Cardiol Croat. 2016;11(10-11):410. | DOI: http://dx.doi.org/10.15836/ccar2016.410

*ADDRESS FOR CORRESPONDENCE: Cantonal Hospital Zenica, Crkvice bb, 72000 Zenica, Bosnia and Herzegovina. / Phone: +387-61-763-330 / E-mail: e.abdovic@gmail.com

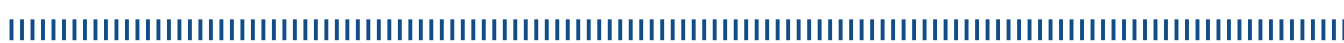
Introduction: Atrial fibrillation (AF) is the most common arrhythmia in adults and is associated with significant morbidity and mortality. An increasing interest exists in identification of noninvasive markers of predisposition to AF. Several ECG and echocardiography-based predictors of AF, such as interatrial block (IAB) and left atrial enlargement (LAE) are well known. ${ }^{1-3}$ Aim of this study was to analyze which noninvasive predictors may help identify patients at risk of developing AF.

Patients and Methods: This was a case-control, observational study which included 9,125 patients evaluated in inpatient or outpatient setting from 2000 to 2016. All subjects underwent 12-lead ECG and transthoracic echocardiogram. AF was defined as an irregularly ECG rhythm without identifiable P wave. IAB was diagnosed if P-wave duration was $\geq 120 \mathrm{~ms}$. LAE was diagnosed in the apical 4-chamber view with LA area $\geq 25 \mathrm{~cm}^{2}$. Demographics and medical history were reported. Patients aged $<18$ years and with long-standing persistent or permanent $\mathrm{AF}$ were excluded. Chi-squared test was used to report differences in frequencies. Binary logistic regression was used to analyze odds ratios for the diagnosis of nonpermanent AF.

Results: There were 798 (8.7\%) cases of nonpermanent AF. Patients in sinus rhythm were more often men (51.8\%), aged <65 years (50.4\%), with frequency of LAE and IAB of $13.3 \%$ and $14.4 \%$, respectively. AF cases were women in $52.6 \%$, aged $\geq 65$ in $75.9 \%$, with $\mathrm{LAE}$ and IAB diagnosed in $32.6 \%$ and $31.1 \%$, respectively. All differences in reported frequencies between patients in sinus rhythm and nonpermanent $\mathrm{AF}$ were statistically significant $(\mathrm{P}<0.001$, except for gender comparison with $\mathrm{P}=0.016)$. The odds for having nonpermanent AF in women was 1.34 (95\% CI 1.13-1.59), in aged $\geq 65$ years was 2.50 (95\% CI 2.07-3.02), and in those with LAE or IAB were 2.50 (95\% CI 2.07-3.03) and 2.11 (95\% CI 1.75-2.56), respectively. Male gender and age < 65 years had odds in favor of sinus rhythm, 0.75 ( $95 \%$ CI $0.63-0.89$ ) and 0.40 (95 CI 0.33-0.48), respectively

Conclusion: $L A E, I A B$, aged $\geq 65$ years, and females were independent, noninvasive markers that may help identify patients at risk of developing AF. P-wave duration and LA area measurements, as modifiable predictors, may contribute substantially to AF risk estimation and should be recommended in a routine workup.

LITERATURE IIIIIIIIIIIIIIIIIIIIIIIIIIIIIIIIIIIIIIIIIIIIIIIIIIIIIIIIIIIIIIIIIIIIIIIIIIIIIIIIIIIIIIIIIIIIIIIIII

1. German DM, Kabir MM, Dewland TA, Henrikson CA, Tereshchenko LG. Atrial Fibrillation Predictors: Importance of the Electrocardiogram. Ann Noninvasive Electrocardiol. 2016;21(1):20-9. DOI: http://dx.doi.org/10.1111/anec.12321

2. Vlachos K, Letsas KP, Korantzopoulos P, Liu T, Georgopoulos S, Bakalakos A,et al. Prediction of atrial fibrillation development and progression: Current perspectives. World J Cardiol. 2016:8(3):267-76. DOI: http://dx.doi.org/10.4330/wic.v8.i3.267

3. Kochhäuser S, Dechering DG, Trought K, Hache P, Haiq-Carter T, Khaykin Y, et al. Predictors for Progression of Atrial Fibrillation in Patients Awaiting Atrial Fibrillation Ablation. Can J Cardiol. 2016 Feb 9. pii: S0828-282X(16)00130-6. DOI: http://dx.doi.org/10.1016/j.cjca.2016.02.031 